\title{
Ueber das Aribin, eine neue organische Base;
}

\author{
von R. Rieth.
}

Die neue organische Base, für die ich den obigen Namen vorschlage, ist in einer brasilianischen Rinde enthalten, die mir Geheimerath v. Martius übergab, mit dem Wunsche, den darin enthaltenen rothen Farbstoff bezüglich seiner technischen Anwendbarkeit untersuchen zu lassen. Die Rinde kommt von einem in den Urwäldern des östlichen Brasiliens wachsenden Baume, der von Martius zuerst botanisch bestimmt und nach dem ursprünglichen indianischen Namen Arariba rubra*) genannt worden ist. Sie ist äulserlich grau, im Innern aber ziemlich schön purpurroth, und wurde schon von den Indianern als Farbmaterial zum Rothfärben der Wolle angewendet. Da nach v. Martius der Baum mit den Cinchoneen verwandt zu sein scheint, einer Gruppe, die durch das Vorkommen verschiedener organischer Basen so merkwürdig und wichtig ist, so schien mir zunächst die Aufsuchung einer solchen in dieser Rinde von grölserem wissenschaftlichem Interesse zu sein, als das Studium des Farbstoffs, das später vorgenommen werden soll. Ich übertrug diese Arbeit Hrn. R. Rieth aus Bonn, dem es nach beharrlichen Versuchen geglückt ist, in dieser Rinde wirklich eine neue, krystallisirbase Base zu entdecken.

Zur Darstellung derselben zeigte sich das folgende Verfahren als das zweckmärsigste : Die zerkleinerte Rinde wurde wiederholt mit schwefelsäurehaltigem Wasser digerirt, die

*) Die Base wl̈re daher eigentlich Araribin zu nennen, allein dieser Name ist unbequem und nicht wohllautend. Mit Arabin, einem ohnehin zu einer ganz anderen Gruppe gehörenden Körper, dürfte wohl das abgekürzte Aribin nicht zu verwechseln sein. 
Auszüge abgeseiht, filtrirt und zusammen bis zu ungefähr $1 / 10$ ihres Volumens abgedampft. Die Flüssigkeil wurde dann mit kohlensaurem Natron nahe gesälligt und mit essigsaurem Blei gefällt, wodurch der gröfste Theil des mit ausgezogenen rothen Farbstoffs niedergeschlagen wurde. Vom Bleisalz wurde ein Ueberschufs zugesetzt, die Flüssigkeit rom Niederschlage abfiltrirt und das Blei dann durch Schwefelwassersloffgas ausgefällt. Hierdurch fiel mít dem Schwefelblei der Rest von Farbstoff nieder, der durch das Bleisạlz nicht ganz ausgefällt werden konnte. Die vom Schwefelblei abfiltrirte Flüssigkeit wurde nun mit kohlensaurem Natron versetzt und dadurch das Aribin noch unrein als hellbraunes Coagulum ausgefällt. Hierauf wurde die ganze Masse mit Aether geschüttelt, welcher die Base aufnahm und sich mit ihr gesättigt als leichtere Flüssigkeitsschicht oben klar abschied. Nachdem er abgehoben worden war, wurde die untere wässerige Schicht wiederholt mit neuem Aether behandelt. Die Aetherlösung, weil sie noch ziemlich stark gefärbt war, wurde nicht abdestillirt, sondern mit Salzsäure geschüttelt, welche die Base aus dem Aether auszog, indem deren salzsaures Salz in letzterem ganz unlöslich ist, dieser aber wenigstens den gröIsten Theil der färbenden Materie aufgelöst behielt. Da es sich gezeigt hatte, dafs das salzsaure Salz in überschüssiger concentrirter Salzsäure unlöslich ist und dadurch krystallinisch gefällt wird, so bot sich hierdurch ein Mittel dar, dasselbe leicht von den noch anhängenden fremden Materien zu trennen. Es wurde dann in Wasser gelöst, das Aribin durch kohlensaures Natron gefältt und durch wiederholtes Krystallisiren aus Aether vollkommen rein erhalten.

Das Aribin bildet farblose Krystalle und krystallisirt in zweierlei Formen, mit und ohne Krystallwasser. Das wasserfreie bildet ziemlich grofse Rhombenoctaëder, das wasserhaltige dagegen lange schmale, meist hohle Prismen, die an 
der Luft unter Verlust des Wassers weifs werden. Das wasserfreie erhält man, wenn die Aetherlösung bei Siedhitze verdunstet wird, das wasserhaltige beim freiwilligen Verdunsten an der Luft. Es enthält $29,03 \mathrm{pC}$. oder $16 \mathrm{Aeq}$. Wasser. Das Aribin besitzt einen sehr bitteren Geschmack, wiewohl es in Wasser sehr wenig löslich ist, und reagirt alkalisch. Es schmilzt bei $229^{\circ}$ ohne Zersetzung und erstarrt wieder krystallinisch. Bei vorsichtigem stärkerem Erhitzen verflüchtigt es sich unzersetzt. Bei der Atomgewichtshestimmung zeigte es sich, dafs es das Chlorwasserstoffsäuregas unter starker Erhitzung aufnimmt. Das salzsaure Salz krystallisirt in glänzenden Prismen, ist in Wasser leicht löslich, in Salzsäure unlöslich. Die Alkalien fällen die Base als weifsen Niederschlag, der namentlich beim Erwärmen rasch krystallinisch wird. Das Platinchlorid-Doppelsalz bildet einen gelben krystallinischen Niederschlag. Von Gerbsäure wird die Base nicht gefällt.

Die von Herrn Rieth ausgeführten Analysen haben zu der unerwarteten Thatsache geführt, dals das Aribin keinen Sauerstoff enthält. Seine Zusammensetzung wird durch die Formel $\mathrm{C}^{46} \mathrm{H}^{20} \mathrm{~N}^{4}$ ausgedrückt; seim Atomgewicht ist 352 . Es ist diefs das erste Beispiel, dafs eine sauerstoffreie, nalürlich vorkommende organische Base ein fester, krystallisirender Körper ist, denn die bisher bekannt gewordenen, das Coniin und Nicotin, sind bekanntlich Flüssigkeiten.

Mit der ausführlicheren Untersuchung namentlich auch der Salze des Aribins ist Herr Rieth gegenwärtig beschäftigt.

$W$. 